\title{
Herpes Zoster in Childhood
}

\author{
Alexander K. C. Leung ${ }^{1,2 *}$, Benjamin Barankin ${ }^{3}$ \\ ${ }^{1}$ University of Calgary, Calgary, Canada \\ ${ }^{2}$ Alberta Children's Hospital, Calgary, Canada \\ ${ }^{3}$ Toronto Dermatology Centre, Toronto, Canada \\ Email: aleung@ucalgary.ca
}

Received 8 February 2015; accepted 3 March 2015; published 6 March 2015

Copyright (C) 2015 by authors and Scientific Research Publishing Inc.

This work is licensed under the Creative Commons Attribution International License (CC BY). http://creativecommons.org/licenses/by/4.0/

(c) (7) Open Access

\begin{abstract}
Herpes zoster is caused by reactivation of latent varicella-zoster virus that resides in a dorsal root ganglion. Herpes zoster can develop at any time after a primary infection or varicella vaccination. The incidence among children is approximately 110 per 100,000 person-years. Clinically, herpes zoster is characterized by a painful, unilateral vesicular eruption in a restricted dermatomal distribution. In young children, herpes zoster has a predilection for areas supplied by the cervical and sacral dermatomes. Herpes zoster tends to be milder in children than that in adults. Also, vaccine-associated herpes zoster is milder than herpes zoster after wild-type varicella. The diagnosis of herpes zoster is mainly made clinically, based on a distinct clinical appearance. The most common complications are secondary bacterial infection, depigmentation, and scarring. Chickenpox may develop in susceptible individuals exposed to herpes zoster. Oral acyclovir should be considered for uncomplicated herpes zoster in immunocompetent children. Intravenous acyclovir is the treatment of choice for immunocompromised children who are at risk for disseminated disease. The medication should be administered ideally within 72 hours of rash onset.
\end{abstract}

\section{Keywords}

Varicella-Zoster Virus, Reactivation, Vesicular Eruption, Dermatome, Acyclovir

\section{Introduction}

Herpes zoster, also known as shingles, is caused by reactivation of endogenous latent varicella-zoster virus that resides in a sensory dorsal root ganglion usually after primary infection with varicella-zoster virus (i.e., varicella

"Corresponding author. 
or chickenpox) [1]. Herpes zoster can develop at any time after a primary infection or varicella vaccination [1]. The activated virus travels back down the corresponding cutaneous nerve to the adjacent skin, causing a painful, unilateral vesicular eruption in a restricted dermatomal distribution.

\section{Epidemiology}

Herpes zoster occurs more commonly after varicella infection than after varicella vaccination [2]. Herpes zoster usually occurs in persons with relative cell-mediated immunologic compromise such as elderly individuals or patients with an immunosuppressive illness or receiving immunosuppressive therapy [3]. The cumulative lifetime incidence among the general population is approximately $10 \%$ to $30 \%$, with the risk increasing sharply after 50 years of age [4]-[6]. In the study by Insigna et al, the overall age- and sex-adjusted incidence of herpes zoster was 320 per 100,000 person-years in the United States from 2000 to 2001 [7]. The rate was higher among females (390 per 100,000 person-years) than among males (260 per 100,000 person-years).The incidence among children aged 0 to 14 years was 110 per 100,000 person-years [7]. Kawai et al performed a systematic review of 63 studies from 22 countries on the incidence of herpes zoster [4]. The authors found the incidence rate of herpes zoster ranged between 300 to 500 per 100,000 person-years in the general population in North America, Europe, and Asia-Pacific, based on studies using prospective surveillance, electronic medical record data or administrative data with medical record review. The incidence is twice in whites when compared to blacks [8]. Immunocompromised individuals have a 20 to 100 times greater risk than immunocompetent individuals of the same age [9] [10].

In general, herpes zoster is uncommon in individuals younger than 10 years of age and rare in infants [3] [5]. The younger a child is when he/she has varicella, the greater the likelihood that herpes zoster will develop in childhood or early adulthood [6]. In this regard, infantile herpes zoster is more commonly associated with intrauterine varicella-zoster virus infection than postnatal infection. In approximately $2 \%$ of children exposed to varicella-zoster virus in utero, subclinical varicella develops, and therefore they are at risk for herpes zoster after birth [3]. Enders et al prospectively followed 1373 women who had varicella during the first 36 weeks of gestation [11]. Herpes zoster in infancy or early childhood was reported in 10 children who were asymptomatic at birth. The observed risk of herpes zoster after maternal varicella between 13 and 24 weeks and between 25 and 36 weeks was $4 / 477$ (0.8\%) and 6/345 (1.7\%), respectively. Eight of these children had herpes zoster during the first year of life.

At times, herpes zoster may result from varicella vaccination as the vaccine strain of varicella-zoster virus may become latent and later reactivate to cause herpes zoster [3] [12] [13]. In one study, the incidence of herpes zoster among varicella vaccine recipients is about 14 cases per 100,000 person-years, compared with 20 to 63 cases per 100,000 person-years after natural varicella infection [14]. In another study, the incidence of laboratory-confirmed herpes zoster was 48 cases per 100,000 person-years in vaccinated children (wild type and vaccine-strain) and 230 cases per 100,000 person-years in unvaccinated children (wild type only) [15]. Several studies have shown that the incidence of herpes zoster in both healthy and immunocompromised children who received varicella vaccine is less than that experienced by healthy and immunocompromised children who experienced natural varicella infection, respectively [12] [15]-[17]. The lower incidence may be related to a lower rate of reactivation of the attenuated vaccine strain of varicella-zoster virus and the lower rate of rash following vaccination compared with wild-type varicella [12].

\section{Pathogenesis}

A primary infection with either wild-type or vaccine-type varicella-zoster virus is a prerequisite for herpes zoster [3]. Activation of latent varicella-zoster virus in a partially immune host results in herpes zoster. Defects in immunity, especially cell-mediated immunity, resulting from an immunosuppressive illness or immunosuppressive therapy are important factors in the pathogenesis. Predisposing factors include increasing age, fatigue, and emotional stress. In children, asthma is a risk factor for herpes zoster [18].

The vaccine-type virus strain is known to establish a latent infection in the dorsal root ganglia [14]. The virus reaches the sensory ganglia through sensory nerves at the injection site. The relative risk of herpes zoster developing in a vaccine recipient is higher in individuals who had a vaccine-associated rash or breakthrough infection [14]. In the majority of cases, the zoster lesions occur on the same side as the vaccine injection site [3]. Varicella vaccine is composed of a mixture of varicella zoster virus strains. Viruses sampled from herpes zoster vesicles are single clones, suggesting that a single strain is selected between the time of inoculation and development of 
the rash [19].

\section{Clinical Manifestations}

The onset of disease may be heralded by pain within the dermatome and precedes the lesions by 48 to 72 hours [1] [12]. The pain is due to acute neuritis and is related to viral replication, inflammation, and cytokine production leading to neuronal destruction and increased sensitivity of pain receptors [20]. At times, there may be paresthesia, burning, or itching in the affected area [12]. An area of erythema might follow and precede the development of a group of vesicles in the distribution of the dermatome that corresponds to the infected dorsal root ganglion (Figure 1) [12]. Usually 1 or, less commonly, 2 or 3 adjacent dermatomes are affected [5] [20]. In young children, herpes zoster has a predilection for areas supplied by the cervical and sacral dermatomes [21]. In adults, the lesions are more common in the lower thoracic and upper lumbar dermatomes and may involve the trigeminal nerve [12]. In both children and adults, the lesions usually do not cross the midline [12]. Vesicles may coalesce to form bullous lesions [1]. The vesicular and bullous lesions may become pustular or occasionally hemorrhagic and ultimately crust in 7 to 10 days [20]. There may be regional lymphadenopathy [12].

Herpes zoster may involve the eyelids when the ophthalmic branch of the trigeminal nerve is affected. Appearance of skin lesions at the side of the nose represents involvement of the nasociliary branch of ophthalmic nerve (Hutchinson's sign) and predicts a higher likelihood of ocular involvement [11] [22].

Herpes zoster tends to be milder in children than in adults [2] [3] [4]. Also, vaccine-associated herpes zoster is milder than herpes zoster after wild-type varicella [2] [3].

In individuals with immunodeficiency, the lesions may involve multiple contiguous, non-contiguous, bilateral,

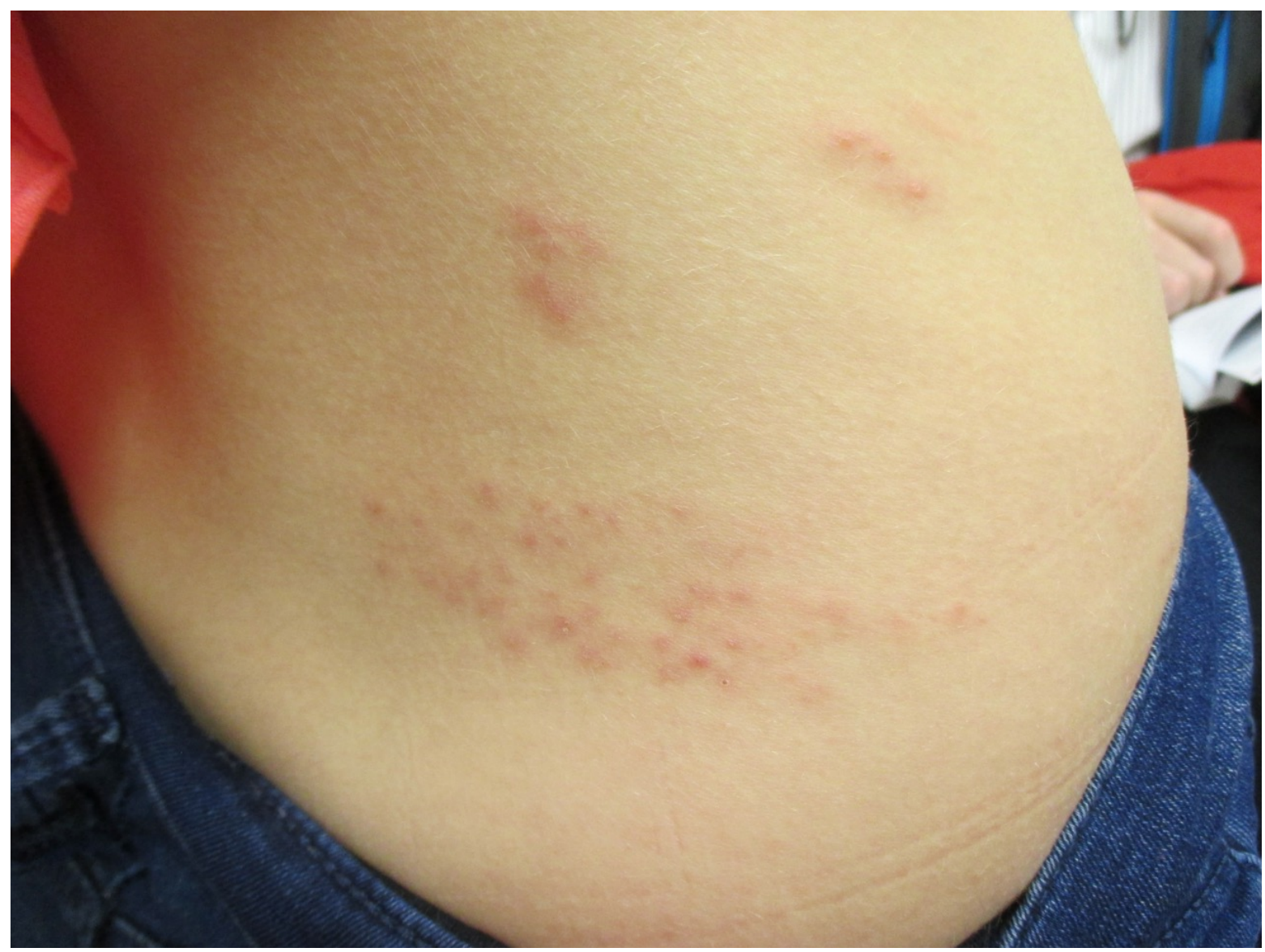

Figure 1. Multiple grouped papules and vesicles on an erythematous base, present unilaterally on the right flank in a dermatomal distribution. 
or unusual dermatomes [4] [12]. The lesions may disseminate to other organs such as the liver, kidneys, lungs, and central nervous system. Also, the illness is more severe and prolonged.

\section{Complications}

The most common complications are secondary bacterial infection, post-inflammatory depigmentation, and scarring [12]. Necrotizing fasciitis is a potential complication if there is secondary bacterial infection [12]. Herpes zoster ophthalmicus may lead to severe eye pain, conjunctivitis, lid ulceration, retinal necrosis, ophthalmoparesis/plegia, sclerokeratitis, anterior uveitis, and optic neuritis [23]. Postherpetic neuralgia, which represents a continuum of pain that does not resolve following the acute episode of herpes zoster, is uncommon in children [1] [2] [5]. Other rare complications include Ramsay Hunt syndrome, Guillain-Barré syndrome, pneumonia, aseptic meningitis, encephalitis, meningoencephalitis, ventriculitis, transverse myelitis, granulomatous cerebral angiitis, cranial nerve paresis/palsies, and peripheral nerve paresis/palsies [17] [20] [24] [25]. Inflammatory skin lesions following herpes zoster may occur within the same dermatome (Wolf's isotopic phenomenon) [12].

Complications are uncommon in vaccine-induced herpes zoster in healthy children. In contrast, in immunocompromised patients, complications are more common and severe.

\section{Diagnosis}

The diagnosis of herpes zoster is mainly made clinically, based on the distinctive clinical appearance and symptomatology. Laboratory tests usually are not necessary. A Tzanck smear, performed by scraping the base of the lesion, can demonstrate giant cells [1]. The diagnosis can be confirmed if necessary by the demonstration of specific viral antigens in skin scrapings or vesicles using direct fluorescent (FDA) assay. Viral DNA analysis of the lesion by polymerase chain reaction (PCR) can be used to distinguish between wild-type and vaccine-type viruses (genotyping) [14].

\section{Differential Diagnosis}

Herpes zoster should be differentiated from zosteriform herpes simplex. In zosteriform herpes simplex, there is no painful prodrome, small vesicles of almost uniform size, less number of grouped vesicles, and more likely to recur. Other differential diagnoses include zosteriform lichen planus, drug eruption, insect bites, folliculitis, hand-foot-mouth disease, contact dermatitis, atopic dermatitis, phytophotodermatitis, and dermatitis herpetiformis.

\section{Prognosis}

Recurrence is uncommon in the immunocompetent individual. Approximately 5\% of immunocompetent patients have a second episode of herpes zoster [5]. Three or more episodes are rare [5] [20].

\section{Management}

Affected patients are contagious because the virus can be transmitted by direct contact with herpes zoster lesions and, less commonly, by airborne spread from aerosolization of virus from skin lesions [11] [14]. Affected children should be kept out of school or day care until crusting appears and contact with pregnant women in particular is to be avoided [1]. Chickenpox may develop in susceptible individuals exposed to herpes zoster [1]. General preventive measures include good personal hygiene, with particular emphasis on hand washing, proper clothing, and covering exposed lesions with bandages. Fingernails should be trimmed to reduce injury from scratching. If secondary bacterial infection occurs, topical or systemic antibiotic therapy is indicated.

The goals of antiviral therapy are to reduce viral shedding, hasten healing of cutaneous lesions, prevent new lesion formation, reduce the pain associated with acute neuritis and possibly decrease complications from the disease [11] [20]. Oral acyclovir (20 mg/kg/dose, maximum $800 \mathrm{mg} / \mathrm{dose}$ ) five times per day for 5 to 7 days should be considered for uncomplicated herpes zoster in immunocompetent children [5]. Intravenous acyclovir (10 mg/kg or $500 \mathrm{mg} / \mathrm{m}^{2}$ every 8 hours) for 7 to 10 days is the treatment of choice for immunocompromised children who are at risk for disseminated disease [1] [5]. The medication should be administered ideally within 72 hours of rash onset [20]. Relapse of herpes zoster can be treated with a second course of acyclovir with similar dosing and duration as for a primary episode. 


\section{Prevention}

It is known that vaccine-associated herpes zoster is milder than herpes zoster after wild type-varicella [26]. As such, there is a need for prevention of varicella-zoster virus infection though universal childhood immunization [26] [27]. The Advisory Committee for Immunization Practices of the Centers for Disease Control and Prevention and the American Academy of Pediatrics recommend a routine two-dose varicella vaccination program for children, with the first dose administered at 12 to 18 months and the second dose at 4 to 6 years of age [2]. The Advisory Committee on Immunization Practices further recommends two doses of varicella vaccine, 4 to 8 weeks apart, for all susceptible adolescents and adults and a catch-up second dose for everyone who receives one dose of varicella vaccine previously [28].

\section{References}

[1] Leung, A.K., Robson, W.L. and Leong, A.G. (2006) Herpes Zoster in Childhood. Journal of Pediatric Health Care, 20, 300-303. http://dx.doi.org/10.1016/j.pedhc.2006.01.004

[2] American Academy of Pediatrics (2012) Varicella Zoster Infections. In: Pickering, L.K., Baker, C.J., Kimberlin, D.W. and Long S.S., Eds., Red Book: 2012 Report of the Committee on Infectious Diseases, 29th Edition, American Academy of Pediatrics, Elk Grove Village, 774-789.

[3] Leung, A.K. (2011) Herpes Zoster. In: Leung, A.K., Ed., Common Problems in Ambulatory Pediatrics: Specific Clinical Problems, Vol. 1, Nova Science Publishers, Inc., New York, 285-289.

[4] Kawai, K., Gebremeskel, B.G. and Acosta, C. (2014) Systematic Review of Incidence and Complications of Herpes Zoster: Towards a Global Perspective. BMJ Open, 4, e004833. http://dx.doi.org/10.1136/bmjopen-2014-004833

[5] LaRussa, P.S. and Marin, M. (2011) Varicella-Zoster Virus Infection. In: Kliegman, R.M., Stanton, B.F., St Geme, J.W., Schor, N.F., Behrman, R.E., Nelson Textbook of Pediatrics, 19th Edition, Elsevier, Philadelphia, 1104-1110. http://dx.doi.org/10.1016/B978-1-4377-0755-7.00245-1

[6] Stein, M., Cohen, R., Bromberg, M., et al. (2012) Herpes Zoster in a Partially Vaccinated Pediatric Population in Central Isreal. Pediatric Infectious Disease Journal, 31, 906-909. http://dx.doi.org/10.1097/INF.0b013e31825d33f9

[7] Insinga, R.P., Itzler, R.F., Pellissier, J.M., et al. (2005) The Incidence of Herpes Zoster in a United States Administrative Database. Journal of General Internal Medicine, 20, 748-753. http://dx.doi.org/10.1111/j.1525-1497.2005.0150.x

[8] Schmader, K., George, L.K., Burchett, B.M., et al. (1995) Racial Differences in the Occurrence of Herpes Zoster. Journal of Infectious Diseases, 171, 701-704. http://dx.doi.org/10.1093/infdis/171.3.701

[9] O’Connor, K.M. and Paauw, D.S. (2013) Herpes Zoster. Medical Clinics of North America, 97, 503-522. http://dx.doi.org/10.1016/j.mcna.2013.02.002

[10] Staikov, I., Neykov, N., Marinovic, B., et al. (2014) Herpes Zoster as a Systemic Disease. Clinics in Dermatology, 32, 424-429. http://dx.doi.org/10.1016/j.clindermatol.2013.11.010

[11] Enders, G., Bolley, I., Miller, E., Cradock-Watson, J. and Ridehalgh, M. (1994) Consequences of Varicella and Herpes Zoster in Pregnancy: Prospective Study of 1739 Cases. The Lancet, 343, 1548-1551. http://dx.doi.org/10.1016/S0140-6736(94)92943-2

[12] Chun, C., Weinman, S., Riedlinger, K., Mullooly, J.P., Houston, H., Schmid, D.S. and Seward, J.F. (2011) Laboratory Characteristics of Suspected Herpes Zoster in Vaccinated Children. The Pediatric Infectious Disease Journal, 30, 719721. http://dx.doi.org/10.1097/INF.0b013e3182137e35

[13] Tseng, H.F., Smith, N., Marcy, S.M., Sy, L.S. and Jacobsen, S.J. (2009) Incidence of Herpes Zoster among Children Vaccinated with Varicella Vaccine in a Prepaid Health Care Plan in the United States, 2002-2008. The Pediatric Infectious Disease Journal, 28, 1069-1072. http://dx.doi.org/10.1097/INF.0b013e3181acf84f

[14] Uebe, B., Sauerbrei, A., Burdach, S. and Horneff, G. (2002) Herpes Zoster by Reactivated Vaccine Varicella Zoster Virus in a Healthy Child. European Journal of Pediatrics, 161, 442-444. http://dx.doi.org/10.1007/s00431-002-0981-1

[15] Weinmann, S., Chun, C., Schmid, D.S., Roberts, M., Vandermeer, M., Riedlinger, K., et al. (2013) Incidence and Clinical Characteristics of Herpes Zoster among Children in the Varicella Vaccine Era, 2005-2009. Journal of Infectious Diseases, 208, 1859-1868. http://dx.doi.org/10.1093/infdis/jit405

[16] Civen, R., Chaves, S.S., Jumaan, A., Wu, H., Mascola, L., Gargiullo, P. and Seward, J.F. (2009) The Incidence and Clinical Characteristics of Herpes Zoster among Children and Adolescents after Implementation of Varicella Vaccination. The Pediatric Infectious Disease Journal, 28, 954-959. http://dx.doi.org/10.1097/INF.0b013e3181a90b16

[17] Rentier, B. and Gershon, A.A., The Members of the European Working Group on Varicella (Euro Var) (2004) Consensus: Varicella Vaccination of Healthy Children: A Challenge for Europe. The Pediatric Infectious Disease Journal, 23, 379-389. http://dx.doi.org/10.1097/01.inf.0000122606.88429.8f 
[18] Kim, B.S., Mehra, S., Yawn, B., Grose, C., Tarrell, R., Lahr, B. and Juhn, Y.J. (2013) Increased Risk of Herpes Zoster in Children with Asthma: A Population-Based Case-Control Study. Journal of Pediatrics, 163, 816-821.

[19] Quinlivan, M.L., Gershon, A.A., Steinberg, S.P. and Breuer, J. (2004) Rashes Occurring after Immunization with a Mixture of Viruses in the Oka Vaccine Are Derived from Single Clones of Virus. The Journal of Infectious Diseases, 190, 793-796. http://dx.doi.org/10.1086/423210

[20] Albrecht, M.A. (2014) Clinical Manifestations of Varicella-Zoster Virus Infection: Herpes Zoster. In: Post, T.W., Ed., UpToDate, UpToDate, Inc., Waltham, MA.

[21] Leung, A.K. and Rafaat, M. (2003) Herpes Zoster. American Family Physician, 67, 1045-1046.

[22] Zaal, M.J., Volker-Dieben, H.J. and D’Amaro, J. (2003) Prognostic Value of Hutchinson's Sign in Acute Herpes Zoster Opthalmicus. Graefe's Archive for Clinical and Experimental Ophthalmology, 241, 187-191. http://dx.doi.org/10.1007/s00417-002-0609-1

[23] De Freitas, D., Martins, E.N., Adan, C., Alvarenga, L.S. and Pavan-Langston, D. (2006) Herpes Zoster Ophthalmicus in Otherwise Healthy Children. American Journal of Ophthalmology, 142, 393-399. http://dx.doi.org/10.1016/j.ajo.2006.03.059

[24] Ong, O.L., Churchyard, A.C. and New, P.W. (2010) The Importance of Early Diagnosis of Herpes Zoster Myelitis. Medical Journal of Australia, 193, 546-547.

[25] Ruppert, L.M., Freeland, M.L. and Stubblefield, M.D. (2010) Segmental Zoster Paresis of the Left Upper Limb in a Pediatric Patient. American Journal of Physical Medicine Rehabilitation, 89, 1024-1029. http://dx.doi.org/10.1097/PHM.0b013e3181e7204b

[26] Leung, A.K. and Barankin, B. (2015) Bilateral Symmetrical Herpes Zoster in an Immunocompetent 15-Year-Old Boy. Case Reports in Pediatrics, 2015, Article ID: 121549.

[27] Leung, A.K., Kellner, J.D. and Davies, H.D. (2009) Chickenpox: An Update. The Pediatric Infectious Disease Journal, 4, 343-350.

[28] Marin, M., Güris, D., Chaves, S.S., Schmid, S. and Seward, J.F., Advisory Committee on Immunization Practices, Centers for Disease Control and Prevention (CDC) (2007) Prevention of Varicella: Recommendations of the Advisory Committee on Immunization Practices (ACIP). The MMWR Recommendations and Reports, 56, 1-40. 